\title{
Trilemma Stability and International Macroeconomic Archetypes
}

\author{
Helen Popper \\ Santa Clara University, CA, USA \\ Alex Mandilaras ${ }^{1, *}$ \\ University of Surrey, Guildford, UK \\ Graham Bird* \\ Claremont McKenna College, CA, USA \\ Claremont Graduate University, CA, USA \\ University of Surrey, UK
}

\begin{abstract}
This paper uses the simple geometry of the classic, open-economy trilemma to introduce a new gauge of the stability of international macroeconomic arrangements. The new stability gauge reflects the simultaneity of a country's choices of exchange rate fixity, financial openness, and monetary sovereignty. So, the new gauge is bounded and correspondingly non-Gaussian. We use the new stability gauge in nonlinear panel estimates to examine the postBretton Woods period, and we find that trilemma policy stability is linked to official holdings of foreign exchange reserves in low income countries. We also find that the combination of fixed exchange rates and financial

\footnotetext{
${ }^{*}$ Corresponding Author.

Email addresses: hpopper@scu.edu (Helen Popper), a.mandilaras@surrey.ac.uk

${ }^{1}$ Postal address: University of Surrey, School of Economics, Guildford, GU2 7XH, UK.
} (Alex Mandilaras), g.bird@surrey.ac.uk (Graham Bird) Tel. no.: +44 1483 682768. Fax: +44 1483689548.
\end{abstract}


market openness is the most stable arrangement within the trilemma; and middle-income countries have less stable trilemma arrangements than either low or high-income countries. The paper also characterizes international macroeconomic arrangements in terms of their semblance to definitive policy archetypes; and, it uses the trilemma constraint to provide a new gauge of monetary sovereignty.

Keywords: Trilemma, Foreign Exchange Rate Regimes, Exchange Rates, International Reserves, Financial Openness, Fear of Floating, Monetary Sovereignty

\section{Introduction}

The classic, open-economy trilemma tells us that a country cannot simultaneously achieve exchange rate stability, capital market openness, and monetary sovereignty. Choosing, say, to peg an exchange rate means choosing to give up some degree of monetary sovereignty, capital market openness, or both. While the trilemma demands that such choices be made, the choices are never final. ${ }^{2}$ This paper introduces a new, formal measure of the stability - or instability - of such arrangements. Based on the constraints of the trilemma itself, the new measure is bounded and drawn from a nonGaussian distribution. As measured here, trilemma policy changes are thus themselves non-normal. This paper uses the new measure to describe the

\footnotetext{
${ }^{2}$ That exchange rate arrangements are not permanent has been highlighted by recent history, emphasized by Obstfeld and Rogoff (1995), and further explored in Calvo and Reinhart (2002), Reinhart and Rogoff (2004), Levy-Yeyati and Sturzeneger (2005), and Ilzetzki et al. (2011). Those papers, among others, document the sometimes dramatic changes in de facto exchange rate regimes. In this paper, we build on such studies of exchange rate stability by encompassing all three legs of the trilemma, rather than just the exchange rate itself.
} 
incidence of policy changes during the post-Bretton Woods period, and it explores the policy changes further using nonlinear panel estimates.

The new measure of stability starts with the simple geometry of the trilemma. We can think of a country's international macroeconomic arrangements in terms of locations in a constrained three-dimensional policy space, one that is defined by exchange rate stability, financial openness, and monetary policy sovereignty. In this framework, the change in a country's arrangement is naturally measured as a movement from one point to another in the three-dimensional policy space. So, the stability or instability of a country's arrangements is reflected in the extent of the changes over time: it is measured by the distances between the sequential locations in the policy space. A stable arrangement is defined as one with relatively small movements within the policy space, while large movements within the policy space represent unstable arrangements.

We also provide a new measure of monetary sovereignty. While there are several existing approaches to measuring capital mobility and exchange rate policy, that is not the case for monetary sovereignty. The extant literature has only one well-used approach to measuring sovereignty. That approach relies on the correlation between a country's interest rate and the interest rate of a base country. One drawback to using such correlations is that they often conflate monetary dependence with other sources of shared dynamics. The new measure presented here does not use interest rate correlations. Instead, it is derived from the trilemma's constraint. The trilemma constrains monetary sovereignty at the expense of exchange rate stability and financial openness. So, given measures of exchange rate stability and financial openness, the trilemma's constraint implicitly provides a measure of monetary sovereignty. This new, implicit measure complements the now-standard 
interest rate correlation approach.

We use the trilemma stability and monetary sovereignty measures to explore which types of trilemma policies are most stable and to study whether official foreign exchange reserves are related to greater trilemma stability. In the next section of this paper, we introduce our new measures, first of stability then of monetary sovereignty. We then use the measures to assess the stability of the trilemma policies in the modern era. Next, we sort countries into policy archetypes in each year and explore the stability of the archetypes. Finally, we examine the links between stability, archetype, and official holdings of foreign reserves.

\section{Two New Measures}

\subsection{A Stability Measure}

To gauge stability, we begin with the international trilemma's standard triad of policies. We denote the $i^{t h}$ country's extant regime in period $t$ as $R_{i, t}$, where:

$$
R_{i, t}=\left(S_{i, t}, F_{i, t}, M_{i, t}\right),
$$

and $S_{i, t}$ represents exchange rate stability, $F_{i, t}$ represents financial openness, and $M_{i, t}$ represents monetary sovereignty. The measures of $S_{i, t}, F_{i, t}$, and $M_{i, t}$, are normalized so that each falls between zero and one (inclusive); and values of one represent perfectly fixed exchange rates, perfectly open financial markets, and perfectly sovereign monetary policy. So, a pure fix with open financial markets is: $R_{i, t}=(1,1,0)$; a pure fix with monetary sovereignty is $R_{i, t}=(1,0,1)$, and a pure float with open capital markets and monetary sovereignty is $R_{i, t}=(0,1,1)$. 
In this framework, a change in a country's regime from one period to the next is simply the vector connecting the two consecutive points in the policy space:

$r_{i, t}=R_{i, t}-R_{i, t-1}=\left(s_{i, t}, f_{i, t}, m_{i, t}\right)=\left(S_{i, t}-S_{i, t-1}, F_{i, t}-F_{i, t-1}, M_{i, t}-M_{i, t-1}\right)$.

Using this vector of policy changes, $r_{i, t}$, we can definitively measure the overall change in policy using the vector's norm, $\left\|r_{i, t}\right\| .^{3}$ Using the norm, we define a single, univariate measure adjusted to fall between zero and one:

$$
n_{i, t}=\frac{\left\|r_{i, t}\right\|}{\sqrt{2}}
$$

This adjusted norm, $n_{i, t}$, captures in a simple scalar the full extent of the change in a country's triad of policies. A value of $n_{i, t}$ equal to zero would mean that a country has not changed its three policies since the previous year. In contrast, a large value of $n_{i, t}$ would reflect a substantial change relative to the prior year.

By reducing three dimensions to one, the norm gauges the stability between periods of the triad of policies within the trilemma. That said, the measure has two potential conceptual drawbacks. First, it requires that we make an assumption about the functional form of the trade-offs between policies. While most open-economy macroeconomic models implicitly in-

\footnotetext{
${ }^{3}$ We use the familiar $l^{2}$-norm, or Euclidean norm. That is, we use: $\left\|r_{i, t}\right\|=\left(s_{i, t}^{p}+\right.$ $\left.f_{i, t}^{p}+m_{i, t}^{p}\right)^{\frac{1}{p}}$, with $p=2$. However, we also calculate the taxi norm, $p=1$, and the infinity norm, $p=\infty$. Despite their different intuitive interpretations (the Euclidean norm is the distance 'as the crow flies,' the taxi norm adds up the full change in each dimension, and the infinity norm takes the largest move in any of the dimensions), the kernel densities of these norms are similarly shaped, and the full sample estimates reported in the panel results below are not sensitive to the use of these alternative norms. We refer to the the $l^{2}$-norm as "the" norm in the rest of the paper.
} 
clude the trilemma as an arbitrage-like condition, various models differ in terms of the functional forms they would imply for the trade-offs among the policies. In this paper, we assume that the trilemma constraint is a linear one in the normalized units that we adopt. ${ }^{4}$ This assumption has the virtue of simplicity, and it is supported empirically by Aizenman et al. (2008) and $\mathrm{Wu}$ (2011). The second potential drawback is that, while the norm provides a gauge of policy stability that reflects the idea that no single policy can be changed on its own, it does not, by itself, retain information about which of the two or three policies has changed. This second drawback can be addressed by using the norm in conjunction with other data. For example, in the empirical work below, we combine the observations of the norm with observations of the trilemma's individual pieces.

By providing a univariate gauge of multivariate changes in policies, our new measure reflects the spirit of the Girton and Roper (1977) 'exchange market pressure' measure. Their measure provided an early, univariate amalgam of foreign exchange policies. Our measure is a similar amalgam, one that now has a geometric interpretation within the well-known trilemma.

[INSERT FIGURE 1 ABOUT HERE]

Figure 1 illustrates our approach to measuring policy stability. The figure displays the two data points underlying a single observation of the adjusted norm, $n_{i, t} \cdot{ }^{5}$ The observation is for Indonesia at the time of the Asian Crisis ( $i=$ Indonesia, and $t=1997)$, and the underlying data are from Aizenman, Chinn, and Ito (2010), which we discuss in more detail in section 3.1. ${ }^{6}$ As is

\footnotetext{
${ }^{4}$ That is, the trilemma can be viewed as a triangular surface in three dimensional space, as illustrated in Online Appendix Figure A1.

${ }^{5}$ Note that the linear version of the trilemma constraint would require that all points lie on the plane defined by the three points: $(0,1,1),(1,0,1)$, and $(1,1,0)$.

${ }^{6}$ This figure uses our new, implicit measure of monetary sovereignty, also described
} 
well-known, Indonesia experienced a substantial increase in its exchange rate variability and a small reduction in its financial openness during the crisis, while it increased its monetary sovereignty considerably. These changes are indicated in the figure by the vector shown between the observations for 1996 and for $1997 .^{7}$ The normalized length of the vector measures the overall change in the policy triad. The norm in 1997 is about five times the values typical of Indonesia earlier in the decade, and it exceeds (by a substantial margin) 95 percent of the values in the sample. After introducing the data, in section 3, we provide additional figures and summary statistics.

In general, the norm of the vector summarizes the overall changes in the policies of the trilemma. Below, we use the norm (adjusted to fall between zero and one) to examine the stability of various policies and to assess the extent to which stability may be linked to official holdings of foreign exchange reserves.

\subsection{An Implicit Measure of Monetary Sovereignty}

The most often-used measure of monetary sovereignty relies on the approach of Shambaugh (2004). That approach reflects the correlation between a country's domestic, short-term interest rate and that of a putative base country, often the United States. High correlations are taken as indicative of monetary dependence. That is, they are taken as a lack of monetary sovereignty. The drawback of this otherwise valuable approach is that, in addition to monetary dependence, the measure also captures the interest rate effects of the underlying circumstances to which independent monetary

below.

${ }^{7}$ The cartesian coordinates $\left(S_{i, t}, F_{i, t}, M_{i, t}\right)$ are $(0.66,0.94,0.4)$ for 1996 and $(0.11,0.88$, 1.0) for 1997. So, $n_{i, t}=0.578$. 
policies may or may not respond. So, at one extreme, even a country with complete monetary sovereignty appears otherwise when it is subject to some of the same shocks or influences as its putative base country. At the other extreme, a country with no monetary sovereignty might misleadingly appear to be quite autonomous when it is subject to disturbances not experienced by its base country.

New Zealand provides a telling example of the standard measure's problem. The Reserve Bank of New Zealand is the prototypic inflation targeter. While it could conceivably be influenced by the policies of Australia (its "base country" in Shambaugh's work), it is in no way constrained by Australia's policies. Nevertheless, the interest rates of New Zealand and Australia are - as one might expect - often highly correlated. So, taken at face value, the standard approach might wrongly seem to suggest that New Zealand's monetary policy is dictated by the Reserve Bank of Australia.

Other researchers, such as Frankel et al. (2004), and Reade and Volz (2010), allow for more general dynamic links between the interest rates of the countries. However, even these more general measures ultimately rely on interest rate comovements, so they are subject to the same drawback. ${ }^{8}$

Here, we introduce an alternative measure of monetary sovereignty that does not suffer from this drawback, and we use the new measure of sovereignty in our gauge of stability, $n_{i, t}$. Our new measure of sovereignty starts from the trilemma itself. Specifically, we maintain our assumption that the trilemma

\footnotetext{
${ }^{8}$ Three other, more recent studies take important steps toward mitigating the problem. Duburcq and Girardin (2010) allow domestic monetary conditions to matter in a study of eight Latin American countries over eleven years. Bluedorn and Bowdler (2010) separate the anticipated and unanticipated components of the base country's interest rate changes using the U.S. as the base country. Herwartz and Roestel (2010) examine long-run interest rate dependence and condition on domestic variables for a panel of 20 small, high income countries.
} 
holds linearly. With that assumption, the existing measures of exchange rate stability, $S_{i, t}$, and of financial openness, $F_{i, t}$, provide us with a very simple, implicit measure of monetary sovereignty, $M_{i, t}$. Specifically, the implicit measure of monetary sovereignty is:

$$
M_{i, t}=2-S_{i, t}-F_{i, t} .
$$

Using data from Aizenman et al. (2010), described in more detail below, Figure 2 depicts both this new measure (the blue lines) and the interest rate correlation measure (the red lines). ${ }^{9}$ Looking at the means, shown in the first row, the new, implicit measure suggests a greater degree of monetary sovereignty than does the interest rate measure. However, underlying these means are individual instances of differences in both directions, as show in the figure's middle row.

\section{[INSERT FIGURE 2 ABOUT HERE]}

For some economies, especially for those that peg exchange rates or maintain them in a narrow band, the new measure often indicates that there is less sovereignty than would be suggested by the interest rate correlation measure. This is the case for Hong Kong, shown in the row's first chart. The Hong Kong Monetary Authority tightly controls the value of exchange rate, and capital is allowed to move into and out of its economy relatively freely. ${ }^{10}$ The trilemma tells us that in such cases there is little scope for

\footnotetext{
${ }^{9}$ In cases where the implicit measure would yield a value in excess of one, we have equated the measure with one. The imposition of this limit reflects the fact that countries not pursuing exchange rate stability and financial openness to the fullest extent nevertheless cannot acquire more than complete $\left(M_{i, t}=1\right)$ monetary sovereignty.

${ }^{10}$ The Hong Kong Monetary Authority has assiduously pegged the Hong Kong dollar to the U.S. dollar since the eighties, and the United States is the base country in Shambaugh (2004).
} 
monetary sovereignty, and in 2010 (the latest year in our sample), the new, implicit measure of sovereignty equals zero. In contrast, differences in the behavior of U.S. and Hong Kong interest rates at times give rise to much higher correlation-based measures of sovereignty despite the tight peg. Hong Kong's correlation-based measure for 2010 is 0.45 , a value that would seem to suggest that Hong Kong retained a good deal of monetary sovereignty, more so even than Australia. ${ }^{11}$ Throughout all of Hong Kong's peg, the new, trilemma-implied sovereignty measures indicate that Hong Kong's monetary sovereignty was more limited than the interest rate correlations would have suggested.

For still other countries, the two sovereignty measures are quite similar; and, the measures occasionally are even identical. For example, both monetary sovereignty measures assign values of zero to eurozone economies in recent years, as illustrated by Austria, shown in the row's next chart. ${ }^{12}$

In some cases, the the new, implicit measure is much larger than the existing, correlation-based measure. For example, returning to the case of New Zealand, shown next, the 2010 interest rate correlation measure is only 0.17 , a value that would seem to suggest that the Reserve Bank of New Zealand follows the monetary policies of Australia. In contrast, New Zealand's new, trilemma-based measure is much higher, 0.71, which reflects its substantial degree of monetary sovereignty. Similarly, Canada's monetary sovereignty (now also used to target inflation) is largely masked by the interest rate measure, which remains low as long as Canadian and U.S. interest rates continue to be relatively highly correlated. Canada's

\footnotetext{
${ }^{11}$ Australia's 2010 correlation-based measure was 0.37 .

${ }^{12}$ In this chart, one can also see the onset of Austria's informal monetary union with Germany in 1981.
} 
measures are shown in the row's last chart. For 2010, Canada's interest rate correlation-based measure is a modest 0.29 , while the implied trilemma measure is 0.72 .

Overall, the sample correlation between the trilemma-based sovereignty measure and the interest rate correlation-based sovereignty measure is 0.37 . The sample correlation between the two measures is higher for high income countries, where it equals 0.53 . It is lowest, 0.15 , for middle income countries; and it is 0.21 for low income countries.

The final row of Figure 2 shows the average changes in the two monetary sovereignty measures. The blue lines depict the changes in the new, implicit measure; and the red lines depict the changes in the interest rate correlation measure. Using the new monetary sovereignty measure, it is now easy to see the monetary upheaval many countries (especially the high income ones, shown in the lower left) experienced in the wake of the Bretton Woods breakdown. By comparison, the correlation-based measures would have suggested that the rich countries experienced only modest changes in their monetary sovereignty. In more recent years, we see that changes in the correlationbased measures suggest a loss in sovereignty among low and middle income economies that does not appear so striking in the new measure.

As might be expected, the sample correlation between the changes in the two sovereignty measures is much smaller (0.04) than the sample correlation of their levels. The pattern across the income groups, however, remains the same. At 0.08 , the correlation between the changes in the two measures is highest for the high-income group. The middle-income group has the lowest correlation, 0.02; while the correlation in the low-income group equals the average, 0.04 .

Overall, while there are some exceptions (such as the Bretton Woods 
breakdown), both the standard deviations in Table 1 and the plots in Figure 2 suggest that the new, implicit measure is somewhat less variable than the old one. That is, using the new, implicit measures, the greater relative sovereignty is ccompanied by a greater steadiness as well.

\section{Data and Overall Trilemma Stability}

\subsection{Data Definition and Descriptive Statistics}

In this section, we calculate the new measures of trilemma stability using a sample of 177 economies with annual data from 1970 through 2010 . We begin with the data provided in Aizenman et al. (2010), updated with the latest version of the de jure financial account openness measure of Chinn and Ito (2006). Then, we recalculate our measure of trilemma stability using our new, implicit gauge of monetary sovereignty.

Aizenman et al. (2010) construct the annual measure of $S_{i, t}$, using the exchange rate's monthly standard deviation against a base country. ${ }^{13,14}$ Like many other researchers, they follow Shambaugh (2004) in constructing monetary sovereignty measures, $M_{i, t}$, using the correlation between each country's money market interest rate and that of its base country. Their measure

\footnotetext{
${ }^{13}$ Aizenman et al. (2010) provide a continuous measure of $S_{i, t}$ that does not rely on the use of reserves to categorize exchange rate regimes. Other prominent de facto measures of exchange rate arrangements include: Shambaugh (2004), and later Klein and Shambaugh (2008), who classify exchange rate arrangements into floating and non-floating; Reinhart and Rogoff (2004), and more recently Ilzetzki et al. (2011), who rely on exchange rate behavior and more nuanced assessments to construct five coarse and many finer categories; and Levy-Yeyati and Sturzeneger (2005), who use information about exchange rates and about reserves to provide a cluster-based exchange rate taxonomy.

${ }^{14}$ Like others, Aizenman et al. (2010) apply a threshold to the standard deviation method in order to allow for currencies that remain in narrow bands; and, they also allow for individual devaluations or revaluations. The base countries include Australia, Belgium, France, Germany, India, Malaysia, South Africa, the United Kingdom, and the United States.
} 
of financial market openness, $F_{i, t}$, is a de jure one: essentially, it is a weighted average of the International Monetary Fund's indicators of exchange restrictions. ${ }^{15}$

Table 1 provides summary statistics for the adjusted norms, $n_{i, t}$, calculated using these data and reported separately for each of the two sovereignty measures. Note that it is the stability of policy that is the focus here, not the stability of the exchange rate. In particular, a sustained float - with its inherent exchange rate volatility - can be part of a stable policy. ${ }^{16}$ The first panel reports the statistics by income group, while the second panel reports them by decade. ${ }^{17}$ The third panel provides the measures for the policy archetypes that are described later in this section. Finally, the bottom panel provides the summary statistics for the sample as a whole.

[INSERT TABLE 1 ABOUT HERE]

The first two columns of numbers report the mean and median for each cat-

\footnotetext{
${ }^{15}$ Specifically, Chinn and Ito (2006) measure financial openness with the first principal component of the IMF's binary indicators of restrictions on current and capital account transactions, of multiple exchange rates, and of the required surrender of export proceeds. This is also the measure subsequently used by Aizenman et al. (2010). Miniane (2004) provides a de jure index that uses finer IMF data on capital account restrictions, but the data are available for only thirty countries. Many other, related, de jure indices have been developed, but few blend the easy interpretation and the wide coverage that Chinn and Ito (2006) provide. The natural alternative is to use actual capital flows as de facto measures of financial openness. However, actual flows are quite volatile from period to period, arguably too volatile to be accurately representing the generally slower moving changes in the underlying policies that are of interest to us here.

${ }^{16}$ To see that a stable policy does not need a stable exchange rate, consider Canada, which has had a floating exchange rate and open capital market for more than two decades. Throughout this period, its exchange rate has fluctuated, but its policy of floating exchange rates and open capital markets has remained the same.

${ }^{17}$ While we examine the full sample of countries, we note that rich economies, middleincome economies, and poor economies differ from one another in many ways that are neither well measured nor well understood. So, imposing constancy may entail questionable restrictions (even when unconditional distributions look broadly similar). Separating the income groups is the simplest way to allow them to differ. The income groupings are available at www.worldbank.org.
} 
egory. In all cases, and using both measures, the means exceed the medians. As we will see with more detail below, this reflects the fact that distributions are skewed to the left and bounded from below by zero. The middle income countries have both the highest means and the highest median. ${ }^{18}$ The norm's maximum values are given in the next column. The largest value, 0.94, belongs to a middle income country: Mexico, which in 1976 abruptly ended its peso fix in exchange for greater monetary sovereignty. The standard deviations show that the norms vary widely throughout all of the subsamples.

The table also provides measures of skewness and kurtosis. As can be seen in the labeled columns, the norms, regardless of how they are split, appear to be strongly leptokurtotic and positively skewed. This can be seen more clearly in Figure 3. The top chart plots non-parametric kernel density estimates of the distributions of the norm for each of the three income groups, and the bottom chart provides comparable plots for each decade in the sample. Both charts show plainly that there are many observations where trilemma policy changes are either small or zero. While very small values are slightly more predominant in the high-income economies, they are prevalent across all three income groups. Likewise, we see a greater concentration of small values in the eighties and the naughts that in the other decades, but the skewness and leptokurtosis are striking in all decades.

\section{[INSERT FIGURE 3 ABOUT HERE]}

Figure 4 graphs the means of the norms over time. The top four charts plot the norms for each of the income groups; and, the red lines show the mean adjusted norms constructed using the interest rate correlation measure of

\footnotetext{
${ }^{18}$ However, Hodges and Lehmann (1963) estimates of the median differences are all zero.
} 
sovereignty, while the blue lines use the new, implied trilemma measure of sovereignty. ${ }^{19}$

[INSERT FIGURE 4 ABOUT HERE]

Overall, the trilemma policies appear to be more stable when that stability is assessed using the new, trilemma-implied monetary sovereignty measure. However, both measures allow us to see the rise in policy changes in low and middle income countries in the nineties - around the time of the Asian financial crisis. Likewise, both measures clearly indicate the policy instability occurring in high-income countries after the fall of Bretton Woods. Throughout most of the remainder of the paper we calculate the norms using the new, trilemma-implied measure of monetary sovereignty. ${ }^{20}$

\subsection{Archetypes}

Next, we explore how the norms differ across the types of trilemma arrangements. We assign observations to four different types of arrangements based on their semblance to one of four "archetypes:" a 'Hong-Kong' type,

\footnotetext{
${ }^{19}$ Online Appendix Table A1 splits the sample according to the dates of some of the key crises that occur during the period: the Mexican Crisis (1994), the Southeast Asian Crisis (1997), and the Argentine Crisis (2002). Summary statistics are provided for each of the subsamples. For the high-income countries, the table reports lower means, medians, maxima, and standard deviations in the later part of the sample than in the early part, regardless of where the split is made. However, the estimated Hodges-Lehmann differences in medians again all equal zero, and the differences for the other income groups are less uniform.

${ }^{20}$ At times, it is the very large changes in policy that are of most interest. So, we separately examine the incidence of large observations. Online Appendix Table A2 provides data on the largest decile of adjusted norms. The table lists the number of these large observations in each year, by income group and for the full sample. In each cell within the table, the numerator gives the number of the large observations, while the denominator gives the total number of observations. Overall, the pattern of large policy changes follows the pattern of the means. The richest economies have the fewest large changes in their trilemma policies, while the middle-income group has the highest proportion of large changes.
} 
with exchange rate stability and open capital markets; a 'China' type, with exchange rate stability and monetary sovereignty; a 'U.S.' type with open financial markets and monetary sovereignty; and a 'Middle' type, with a modest degree of all three characteristics.

We use the simple geometry of the trilemma to describe the types of arrangements more precisely. Letting $j=$ 'Hong Kong', 'China', 'U.S.', 'Middle', we define type $j$ such that $R_{j}$ takes on the values: $(1,1,0),(1,0,1)$, $(0,1,1)$, and $\left(\frac{2}{3}, \frac{2}{3}, \frac{2}{3}\right)$. Each of these four values of $R_{j}$ represents a point on the frontier of the feasible set defined by the trilemma. The first three points represent the three corners corresponding to the 'Hong Kong, 'China,' and 'U.S.' archetypes described above, and the last point represents the 'Middle' of the feasible frontier. Then, we define country $i$ 's type in period $t$ by its proximity to one of the four points. Specifically, we let:

$$
\begin{gathered}
j=\underset{j}{\operatorname{argmin}}\left\|\left(R_{i, t}-R_{j}\right)\right\| \\
\text { type }_{i, t} \stackrel{\text { def }}{=} \text { type }_{j} .
\end{gathered}
$$

That is, the observation's type is defined by the one that minimizes the distance between the observation and the archetype. ${ }^{21}$

Throughout much of the modern period, the most common arrangement in this taxonomy is the 'China' type, with its relatively stable exchange rates and a relatively high degree of monetary sovereignty. The second most common arrangement type is the 'Middle.' The number of 'Middle'

\footnotetext{
${ }^{21}$ Using this definition of assigned types, Figure A2 in the online appendix shows the number of economies in each year of each type. In our sample, the observations of the Chinese, Hong Kong, and U.S. economies do not precisely mimic the zero or one values of their corresponding archetypes, but they are close.
} 
observations rose through the early nineties as many 'China' type economies began to relax some of their capital controls. The number of economies of the 'Hong Kong' type has been rising fairly steadily since the nineties. The number of economies of the 'U.S.' type has risen throughout the period, though less steadily. ${ }^{22}$

[INSERT FIGURE A2 ABOUT HERE]

Next, we examine the stability of the archetypes by looking at the norms in each category. Specifically, for each observation, we note the archetype and observe the extent of the trilemma policy change over the subsequent year.

The third panel of Table 1 summarizes the adjusted norm for the four types of arrangements. As shown, the economies that fall within the fixed exchange rate archetypes, 'China' and 'Hong Kong', are the ones that have the smallest means and medians. ${ }^{23}$ Notably, the median of the observations in the 'Hong Kong' archetype is zero. Underlying this statistic is the fact that about two-thirds of the norms in the Hong Kong' category are zero. ${ }^{24}$

\footnotetext{
${ }^{22}$ These findings can be interpreted as confirmation that there has been no sustained 'hollowing out of the middle,' where the 'middle' is now defined in the three-dimensional context of the trilemma. Suggested first in the nineties, the 'hollowing out' argument was that increasing capital mobility would make intermediate exchange rate regimes unsustainable; so governments would be forced to choose between zero and full exchange rate stability. Frankel et al. (2001) and others later refuted the argument empirically by noting that policies of modest exchange rate stability were holding their own against the extremes of fixity and floating. The bulk of the literature focused exclusively on the single dimension of exchange rate policy. Here, one can define the 'middle' and the 'poles' in terms of all three policy dimensions we likewise find that the hollowing out idea is not supported. The approach builds on the findings of Aizenman, Chin, and Ito, who show that emerging market economies have moved toward a blend of policies.

${ }^{23}$ Hodges-Lehmann estimates (not reported in the table) of the pseudo median differences between each archetype and the remainder are nonzero for all four categories.

${ }^{24}$ Note that there is nothing inherent in the 'Hong Kong' type that necessitates that it is the most stable policy configuration. We can see this by way of example. Consider Argentina in 2001, when it was characterized as a 'Hong Kong' type in 2001. This archetype's policy triad was not sustained. Although Argentina retained a fixed exchange
} 
That is, economies with relatively fixed exchange rates and open capital markets often keep their policies the same from one year to the next. Correspondingly, 'Hong Kong' is also the archetype with the greatest leftward skewness, shown in the designated column. The 'China' archetype, which has relatively closed financial markets, is also heavily skewed to the left, with a low median, and many (about forty percent) of its norms equal to zero. The 'U.S.' archetype, in which exchange rates are flexible and financial markets are open, and the 'Middle' archetype, which has some of that openness and flexibility, have higher means and medians. That is, not only do these last two archetypes have more variable exchange rates, they also have more variable trilemma policies.

The bottom rows of Figure 4 illustrate how stability has changed over the modern period for each of the archetypes. Despite the obvious peaks in the mean adjusted norms of the 'China' and 'Hong Kong' archetypes in the late nineties, these archetypes (which have exchange rate stability in common) exhibit the smallest overall policy changes; and, their relative stability has been largely sustained throughout the global financial crisis. While the norms of the 'U.S.' archetype countries have fallen over the modern era as a whole, they - along with the norms of the 'middle' category - have been relatively high.

\section{Panel Regressions}

This section uses panel estimates to explore the relationship between stability and the underlying trilemma policies. The bounded nature of the

rate between 2001 and 2002, it changed its financial openness and monetary sovereignty considerably, which gave it a large norm: $n_{i, t}=0.59$. This value differs only slightly from Indonesia's large norm at the time of the Asian Crisis. 
adjusted norm raises a number of econometric issues that render the use of linear models potentially problematic. ${ }^{25}$ Papke and Wooldridge (2008) propose a solution to this problem in a panel context, and the estimation here relies on their approach. Their solution employs a generalized estimation equation (GEE) in a balanced panel.

Using this approach, two specifications are estimated with a balanced panel of 96 countries between $1985-2010 .{ }^{26}$ Both specifications relate the norm to the underlying trilemma policies and to official holdings of foreign exchange reserves. ${ }^{27}$

The first specification relates the adjusted norm to past reserves and past measures of exchange rate stability and of financial openness. The second specification also includes lagged reserves, but instead of including the measures of exchange rate stability and openness, it includes dummies for the economy's lagged archetype.

Specifically, GEE estimates are provided for two versions of Papke and Wooldridge's (2008) fractional panel model:

$$
E\left(n_{i t} \mid \mathbf{x}_{i 1}, \ldots, \mathbf{x}_{i T}\right)=\Phi\left(\kappa_{t}+\mathbf{x}_{i t} \beta+\overline{\mathbf{x}}_{i} \lambda\right)
$$

where $\mathbf{x}_{i t}$ is the vector of explanatory variables; $\overline{\mathbf{x}}_{i}$ is the corresponding vector of country-specific means; $\kappa_{t}, \beta$, and $\lambda$ are scaled coefficients; and, the time subscript in $\kappa_{t}$ indicates the use of a complete set of time dummies. The

\footnotetext{
${ }^{25}$ For details see Papke and Wooldridge (1996).

${ }^{26} \mathrm{An}$ online appendix lists the countries that are included in the balanced panel.

${ }^{27}$ The consideration of reserves reflects a long tradition of studying their links to trilemma policies. Beginning with the early work on optimal reserves in a stochastic setting (for example: Kenen and Yudin (1965) and Heller (1966)), economists have modeled reserves as potentially reducing the probability or cost of devaluations, of speculative attacks, and of sudden stops. Their inclusion here allows for such a role. Data are taken from the World Bank's World Development Indicators.
} 
inclusion of $\overline{\mathbf{x}}_{i}$ allows for time-constant, unobserved country effects that may be related to our other regressors, while it avoids the incidental parameters problem raised by cross-sectional dummies in this context. ${ }^{28}$ In the first specification, $\mathbf{x}_{i t}=\left[\rho_{i, t-1}, s_{i, t-1}, f_{i, t-1}\right]$; and, in the second specification,

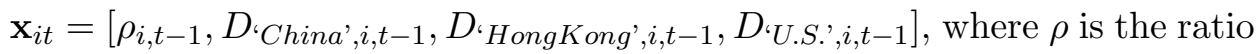
of official reserves to GDP, and $D_{j}$ indicates a dummy variable for type $e_{i, t}=$ $R_{j}{ }^{29}$

Panel estimates are first presented using the full range of policy changes, and the three income groups are treated separately. The focus then turns to large policy changes exclusively, where 'large' is defined in terms of several cutoffs of the value of the norm.

\subsection{Estimation by Income Group}

The top two panels of Table 2 provide the estimation results from the two specifications for each income group. The top panel gives the estimates from the specification using the exchange rate stability and financial market openness as regressors; and, the second panel gives the estimates from the specification that makes explicit use of the archetypes. Each pair of columns gives the estimated coefficients, along with their standard errors - which are robust to second order misspecification - and the partial effects, averaged across the population (APEs), with bootstrapped standard errors. ${ }^{30}$

\section{[INSERT TABLE 2 ABOUT HERE]}

The results for low-income economies are given in the first pair of columns; and, the first row in each panel gives the estimates for reserves as a fraction

\footnotetext{
${ }^{28}$ Lancaster (2000) provides a survey of the literature on the incidental parameters problem.

${ }^{29}$ Note that $R$ Middle' is subsumed by the constants in the second specification.

${ }^{30}$ For a discussion of APEs, see chapter 2 in Wooldridge (2010).
} 
of GDP. In both specifications, the estimated coefficients are negative and statistically significant at the five percent level. The estimated APEs, which (unlike the raw coefficients) can be compared across specifications, are of roughly similar magnitudes: 0.34 in the first specification and 0.40 in the second. These estimates imply that in low-income economies greater reserves tend to come with greater trilemma policy stability.

The low-income estimates for the first specification's remaining variables, the degree of exchange rate stability and the degree of financial openness, are given with their standard errors in the subsequent rows of the top panel. None is statistically significantly different from zero at any standard confidence level. The low-income archetype estimates are given in the remaining rows of the second panel. As shown, the coefficient on the 'Hong Kong' archetype is positive and mildly statistically significant. This implies that (conditional on reserves), the combination of open capital markets and fixed exchange rates does not represent a particularly stable policy configuration among low income economies.

The next pair of columns provides the estimates for the middle income economies. Here, reserves are no longer statistically significant. However, in the first specification, we see that (in the third row) exchange rate stability has a negative coefficient and is mildly significant. That is, conditional on the reserves and the degree of financial openness, we are somewhat more likely to find smaller policy disruptions in middle-income economies when they have relatively more stable exchange rates. In the second specification, we see that the middle-income coefficient on the 'USA' archetype is positive and and mildly significant. That is, conditional on reserves and financial openness, larger policy changes are found here when exchange rates are flexible. The positive coefficient (implying a higher norm) on the 'U.S.' 
archetype in this specification goes hand in hand with the negative coefficient (implying a lower norm) on exchange rate stability in the first specification.

The third pair of columns gives the estimates for the high-income economies. The estimated coefficients on reserves are positive and significant in both specifications. In the first specification, the estimated coefficient on exchange rate stability is negative, as it is in for middle-income economies, and here it is statistically significant at the one percent level. Correspondingly, in the second specification, the coefficient on the 'Hong Kong' archetype is negative and statistically significant at all confidence levels.

Finally, the last pair of columns gives the estimates for the full sample. Taken as a whole, reserves lose all significance in the first specification, but the estimated coefficient on exchange rate stability is negative and significant. Likewise, the coefficient on reserves is small and insignificant in the second specification, but the coefficient on the 'Hong Kong' archetype is again negative and strongly statistically significant.

\subsection{Large Norms}

The bottom of the table provides the results from the same specifications estimated only for 'large' policy changes. The first pair of columns report estimates using norms from the top decile of the distribution; and, subsequent columns provide estimates where the definition of 'large' is broadened to include additional deciles, until all the values of the norm above the median are included.

The first row of each panel again gives the estimated reserve parameters. In both specifications, and for all definitions of 'large', the estimated coefficients on reserves are negative, though there is only mild statistical significance for the top decile estimates, and none elsewhere. Recall that the 
APE estimates, unlike the raw coefficient estimates, can be compared across specifications. In the first specification the estimated APE is -0.37 , and in the second specification it is -0.42 . These values do not differ markedly from the earlier low-income APE estimates of -0.34 and -0.40 .

The negative link between reserves and trilemma stability that we see here in times of instability, and for low-income economies, may reflect a greater incidence of limitations on governments' access to international financial markets. With limited access to credit, the governments in such economies must rely more heavily on their own reserves when funds are needed to smooth policies. ${ }^{31}$

The estimates for exchange rate stability and financial market openness are given next. The estimated exchange rate stability coefficients are uniformly positive for the large norms. That is, there is some tendency to find large policy changes in conjunction with greater exchange rate stability. These positive estimates contrast with the negative full sample estimates above. The statistical significance of the exchange rate is limited here to the samples that include the top 30 percent and the top 40 percent. One possible interpretation of these results is that fixed exchange rates are usually part of relatively stable policies, but when they are associated with policy changes, those changes are somewhat large.

The estimated coefficients on financial market openness are given next. The coefficients again are all negative; and they are significant here at the one percent level for all but the top decile. This tells us that, conditional on reserves and the degree of exchange rate stability, trilemma policies are

\footnotetext{
${ }^{31}$ As mentioned above, such policy smoothing is typically optimal in models with convex policy costs. See, for example, Pina (2012) for a model of developing country reserves in a monetary policy context.
} 
more stable when financial markets are open.

Among the archetypes, given next, only the 'China' estimates are statistically significant at standard confidence levels. The 'China' estimates are uniformly positive, and they are statistically significant for all definitions of 'large', except the top decile. The positive 'China' coefficients echo the earlier findings for exchange rate stability and financial openness in that the 'China' archetype represents the combination of relatively stable exchange rates and relatively closed financial markets. That is, both these qualities are associated with relatively large policy changes.

\section{Conclusions}

Underlying this paper is a willingness to use the constraint of the classic, open-economy trilemma and to draw out some of its implications for empirical work on the stability of trilemma policies. The simple geometry of the trilemma is used to provide a univariate gauge of the stability of a country's multidimensional international macroeconomic policies. The new gauge is bounded by the constraints of the trilemma itself, and it is nonGaussian. Most importantly, the distribution is asymmetric. Future studies of trilemma policy stability - whether studies of its determinants or its consequences - should recognize and incorporate this fundamental asymmetry.

In addition to the new trilemma stability gauge, the paper provides a new, implicit measure of monetary sovereignty; and it illustrates a framework for characterizing international macroeconomic arrangements in terms of their semblance to definitive policy archetypes. The monetary sovereignty measure is constructed from the trilemma's constraint in conjunction with existing measures of exchange rate stability and international financial open- 
ness. The international macroeconomic policy characterizations stem from their positioning within the trilemma's policy space.

The paper's approach and its resulting measures are used here to characterize the international macroeconomic arrangements of the modern era. The measures indicate that international macroeconomic policies have been most stable in settings of relatively fixed exchange rates and open financial markets. Using the new monetary measures, it appears that for many countries monetary sovereignty has been both somewhat greater and somewhat less erratic than previously had been thought. Finally, when attention is restricted to large policy changes or to low-income economies, the stability of international macroeconomic policies also appears to be linked to official holdings of foreign exchange reserves.

\section{Acknowledgements}

We gratefully acknowledge financial support from the British Academy, grant RF1049. We wish to thank three anonymous referees and participants at the following conferences and workshops: SCE conference, San Francisco; SCIES conference, University of California at Santa Cruz; University of Texas, Houston; Charles University, Prague; Portland State University, Oregon; SIRE and CEFS conference, University of Glasgow; INFINITI con-

ference, University of Dublin; Claremont McKenna College; Santa Clara University; University of Washington; California Polytechnic University; and the Central Bank of Chile.

Aizenman, J., Chinn, M. D., Ito, H., 2008. Assessing the emerging global financial architecture: Measuring the trilemma's configurations over time. NBER Working Paper No. 14533, National Bureau of Economic Research. 
Aizenman, J., Chinn, M. D., Ito, H., 2010. The emerging global financial architecture: Tracing and evaluating new patterns of the trilemma configuration. Journal of International Money and Finance 29 (4), 615-641.

Bluedorn, J. C., Bowdler, C., 2010. The empirics of international monetary transmission: Identification and the impossible trinity. Journal of Money, Credit and Banking 42 (4), 679-713.

Calvo, G. A., Reinhart, C. M., 2002. Fear of floating. The Quarterly Journal of Economics 117 (2), 379-408.

Chinn, M., Ito, H., 2006. What matters for financial development? Capital controls, institutions, and interactions. Journal of Development Economics 81 (1), 163-192.

Duburcq, C., Girardin, E., 2010. Domestic and external factors in interest rate determination: The minor role of the exchange rate regime. Economics Bulletin 30 (1), 624-635.

Frankel, J., Schmukler, S. L., Serven, L., 2004. Global transmission of interest rates: Monetary independence and currency regime. Journal of International Money and Finance 23 (5), 701-733.

Frankel, J. A., Fajnzylber, E., Schmukler, S. L., Serven, L., 2001. Verifying exchange rate regimes. Journal of Development Economics 66 (2), 351386.

Girton, L., Roper, D., 1977. A monetary model of exchange market pressure applied to the postwar Canadian experience. The American Economic Review 67 (4), 537-548. 
Heller, H. R., 1966. Optimal international reserves. The Economic Journal 76 (302), 296-311.

Herwartz, H., Roestel, J., 2010. Are small countries able to set their own interest rates? Assessing the implications of the macroeconomic trilemma. Economics Working Papers ECO2010/09, European University Institute.

Hodges, J. L., J., Lehmann, E. L., 1963. Estimates of location based on rank tests. The Annals of Mathematical Statistics 34 (2), pp. 598-611.

Ilzetzki, E., Reinhart, C., Rogoff, K., 2011. The country chronologies and background material to exchange rate arrangements in the 21st century: Which anchor will hold? Working paper, London School of Economics.

Kenen, P. B., Yudin, E. B., 1965. The demand for international reserves. Review of Economics and Statistics 47, 242-250.

Klein, M. W., Shambaugh, J. C., 2008. The dynamics of exchange rate regimes: Fixes, floats, and flips. Journal of International Economics 75 (1), 70-92.

Lancaster, T., April 2000. The incidental parameter problem since 1948. Journal of Econometrics 95 (2), 391-413.

Levy-Yeyati, E., Sturzeneger, F., 2005. Classifying exchange rate regimes: Deeds vs. words. European Economic Review 49 (6), 1603-1635.

Miniane, J., 2004. A new set of measures on capital account restrictions. IMF Staff Papers 51 (2), 276-308.

Obstfeld, M., Rogoff, K., 1995. The mirage of fixed exchange rates. Journal of Economic Perspectives 9 (4), 73-96. 
Papke, L. E., Wooldridge, J. M., 1996. Econometric methods for fractional response variables with an application to 401(k) plan participation rates. Journal of Applied Econometrics 11 (6), 619-32.

Papke, L. E., Wooldridge, J. M., 2008. Panel data methods for fractional response variables with an application to test pass rates. Journal of Econometrics 145 (1-2), 121-133.

Pina, G., 2012. The recent growth of international reserves in developing economies: A monetary perspective. Job market paper, Universitat Pompeu Fabra.

Reade, J. J., Volz, U., 2010. Chinese monetary policy and the dollar peg. Discussion Paper 35, Free University Berlin, School of Business \& Economics.

Reinhart, C. M., Rogoff, K., 2004. The modern history of exchange rate arrangements: A reinterpretation. Quarterly Journal of Economics 119 (1), $1-48$.

Shambaugh, J. C., 2004. The effect of fixed exchange rates on monetary policy. Quarterly Journal of Economics 119 (1), 300-351.

Wooldridge, J. M., 2010. Econometric Analysis of Cross Section and Panel Data. Vol. 1. The MIT Press.

Wu, T., 2011. De facto index of monetary policy domestic activism and inefficient trilemma configurations in OECD countries. Working paper, UC Santa Cruz. 


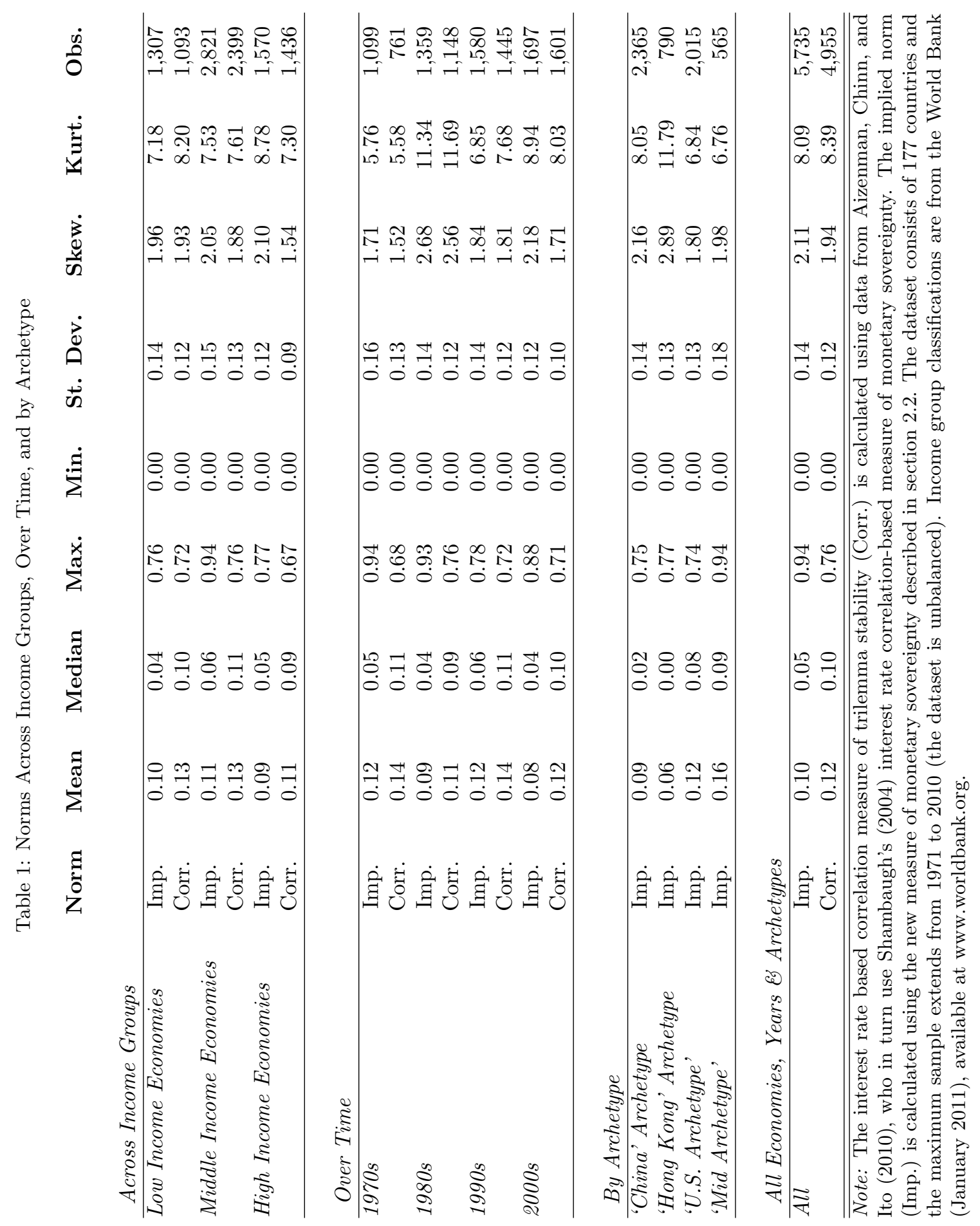



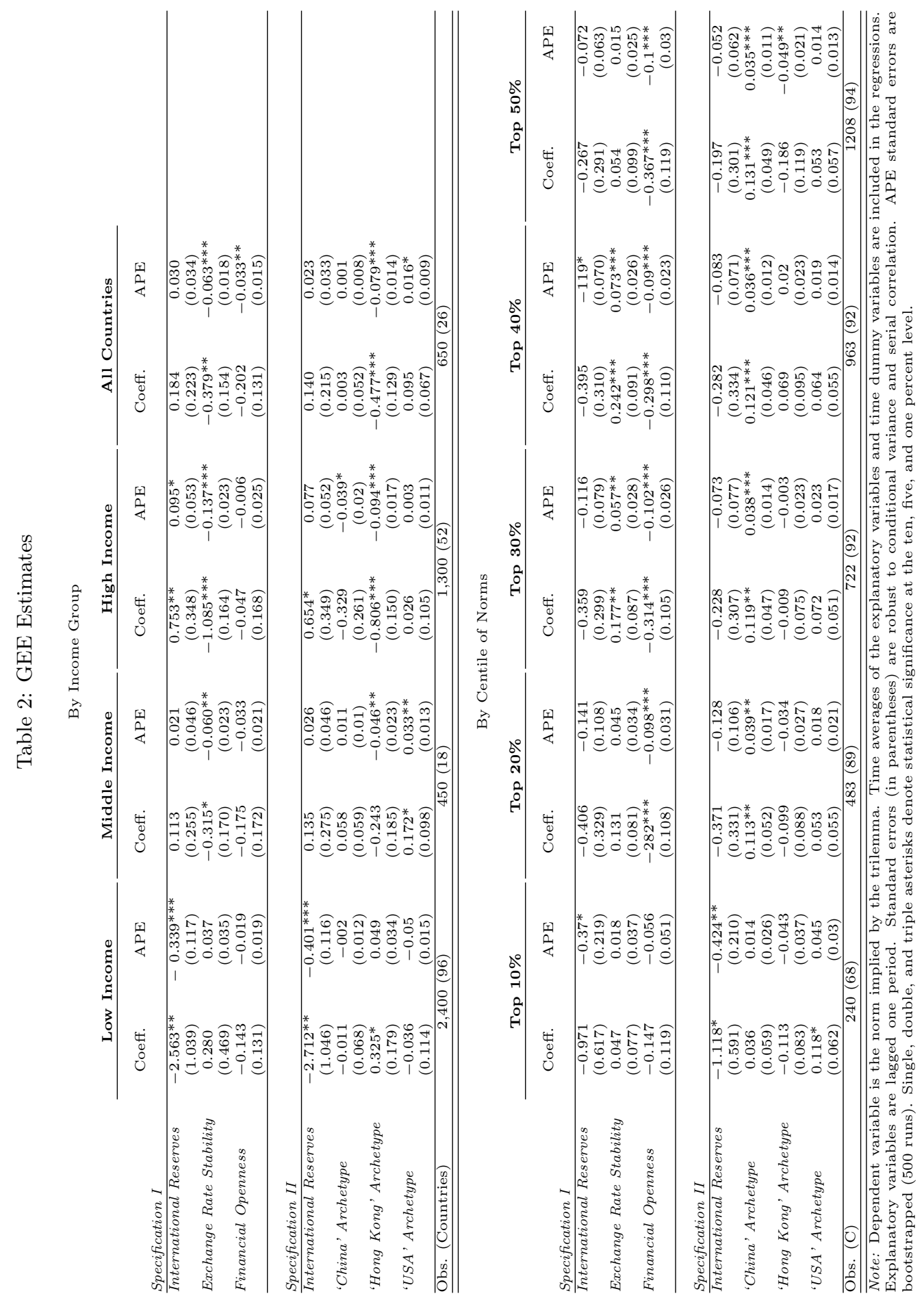


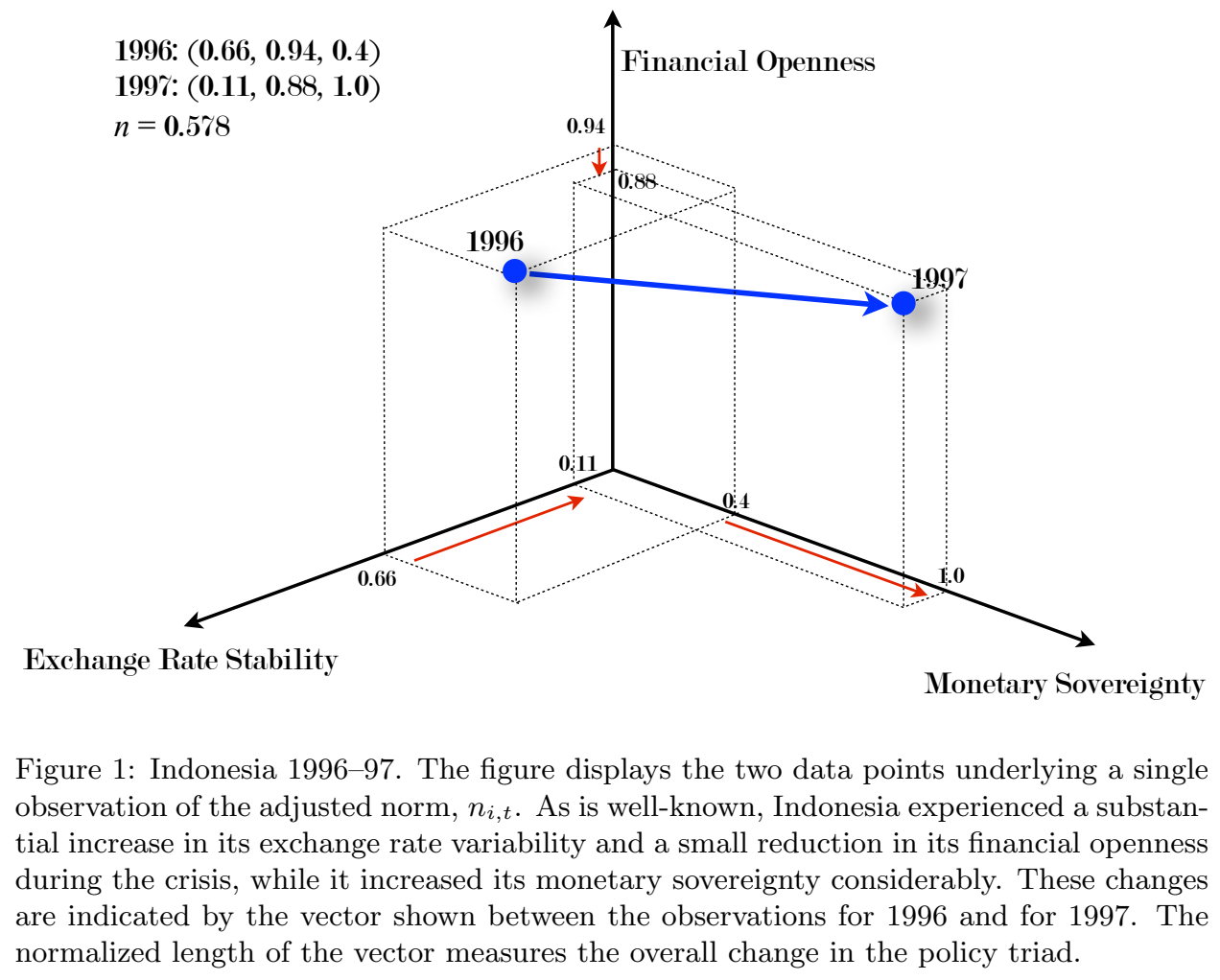




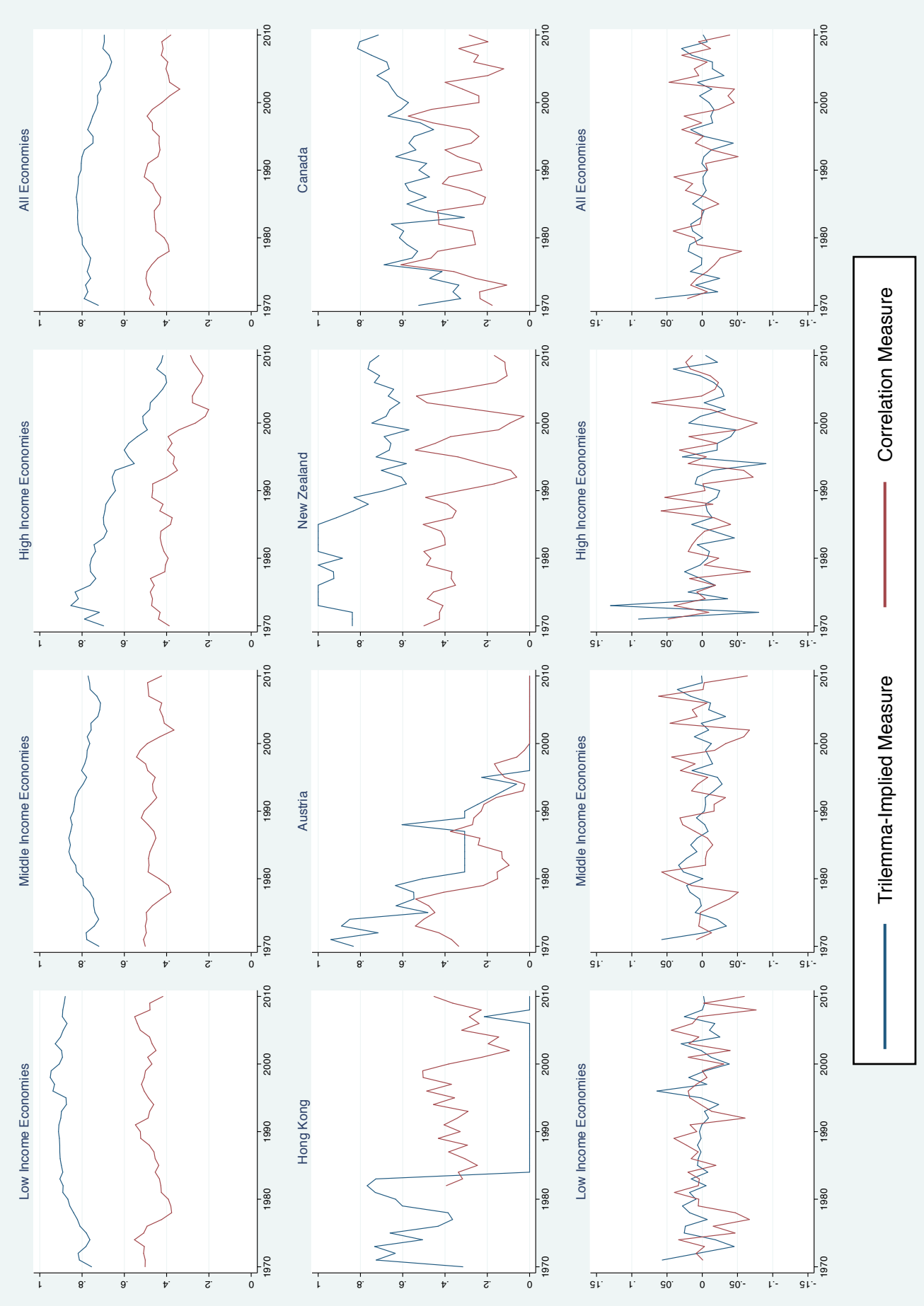

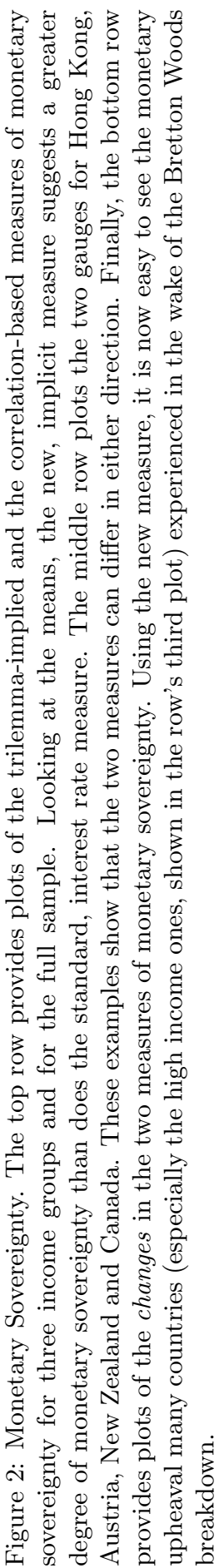




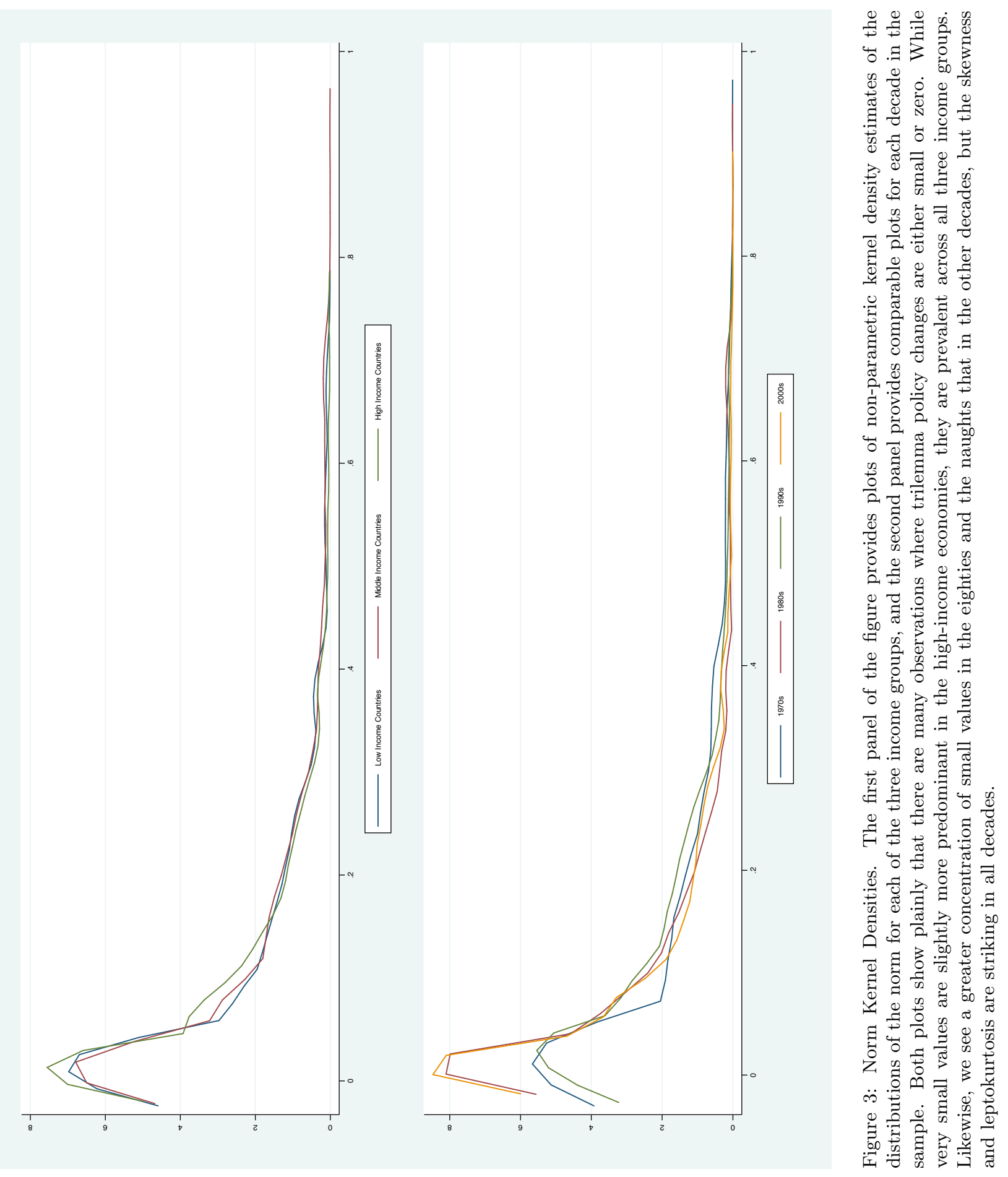




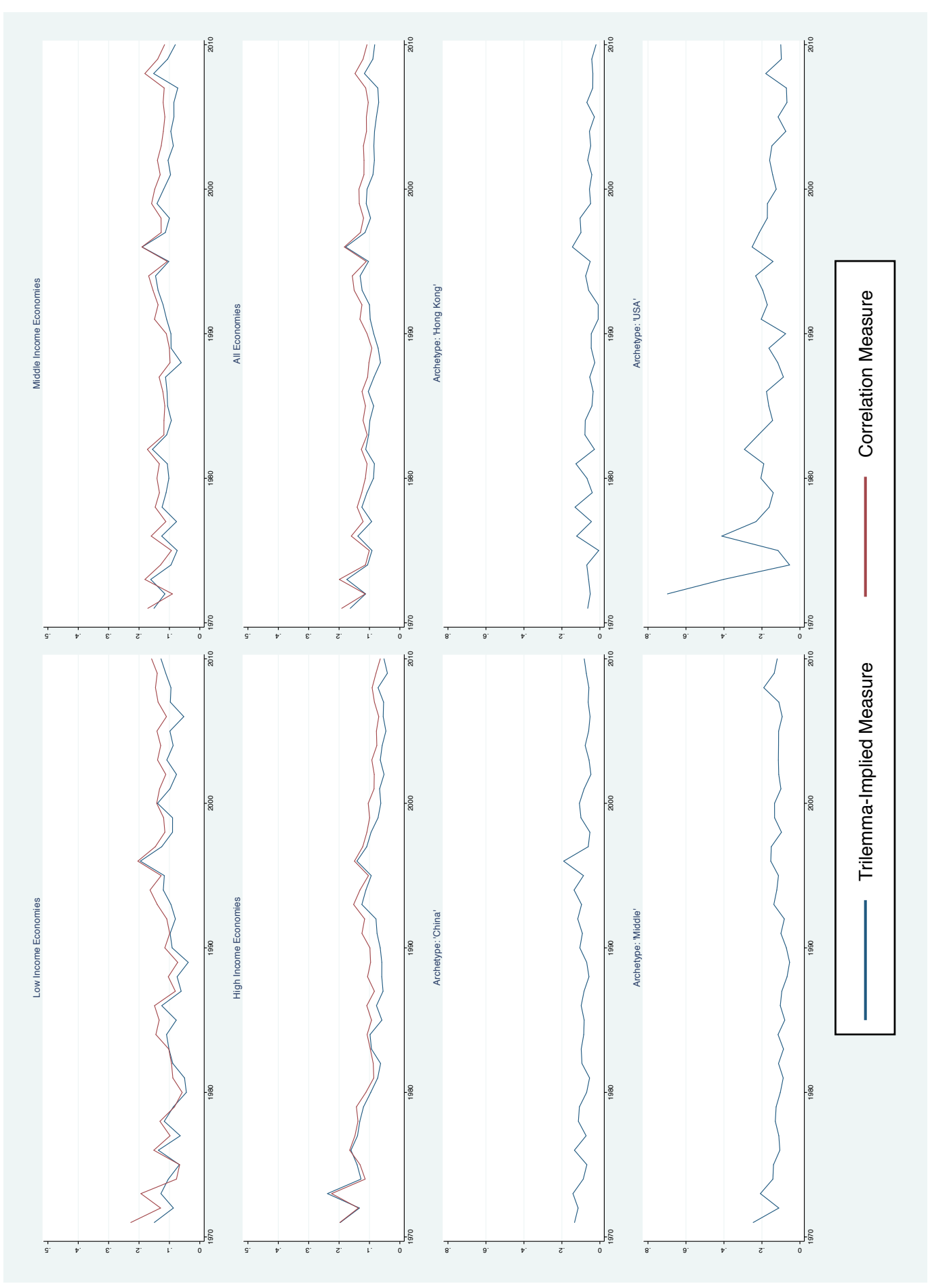

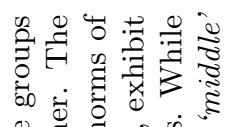

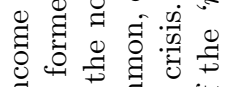

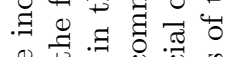

ॠ

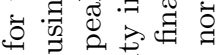

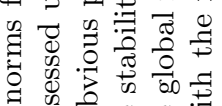

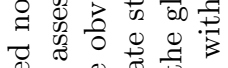

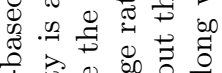

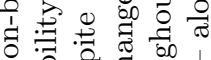

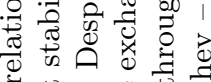

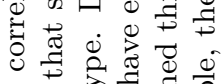

चี

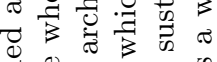

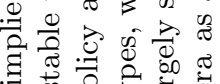

需䨔:

当

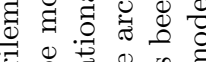

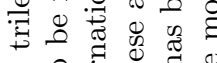

웜원

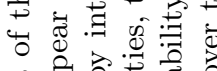

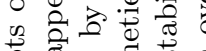

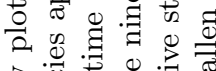

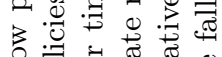

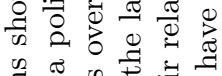

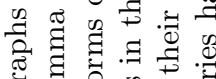

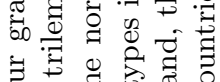

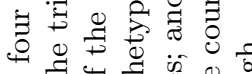
क्ष

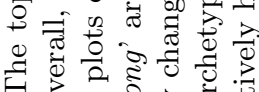

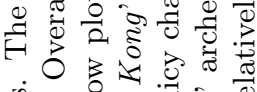
过

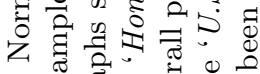

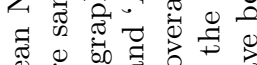

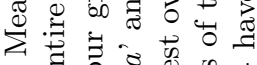
ㅎ Ð

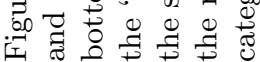




\section{A. ON-LINE APPENDIX}

Table A1: Norms Before and After Recent Crises

\begin{tabular}{|c|c|c|c|c|c|c|c|c|c|}
\hline & Group & Mean & Median & Max. & Min. & St. Dev. & Skew. & Kurt. & Obs. \\
\hline \multirow[t]{4}{*}{$1971-1994$} & LIC & 0.09 & 0.02 & 0.69 & 0.00 & 0.14 & 2.18 & 8.00 & 689 \\
\hline & MIC & 0.11 & 0.05 & 0.94 & 0.00 & 0.16 & 2.11 & 7.49 & 1390 \\
\hline & $\mathrm{HIC}$ & 0.10 & 0.06 & 0.77 & 0.00 & 0.13 & 2.08 & 8.56 & 818 \\
\hline & All & 0.10 & 0.05 & 0.94 & 0.00 & 0.15 & 2.17 & 8.12 & 2897 \\
\hline \multirow[t]{4}{*}{$1995-2010$} & LIC & 0.11 & 0.06 & 0.76 & 0.00 & 0.13 & 1.72 & 6.32 & 618 \\
\hline & MIC & 0.11 & 0.06 & 0.88 & 0.00 & 0.14 & 1.93 & 7.23 & 1431 \\
\hline & $\mathrm{HIC}$ & 0.07 & 0.03 & 0.68 & 0.00 & 0.10 & 1.97 & 7.38 & 789 \\
\hline & All & 0.10 & 0.05 & 0.88 & 0.00 & 0.13 & 1.98 & 7.63 & 2838 \\
\hline \multirow[t]{4}{*}{$1971-1997$} & LIC & 0.10 & 0.03 & 0.69 & 0.00 & 0.14 & 2.01 & 7.15 & 790 \\
\hline & MIC & 0.12 & 0.05 & 0.94 & 0.00 & 0.16 & 2.00 & 6.99 & 1617 \\
\hline & $\mathrm{HIC}$ & 0.11 & 0.06 & 0.77 & 0.00 & 0.13 & 2.00 & 8.32 & 938 \\
\hline & ALL & 0.11 & 0.05 & 0.94 & 0.00 & 0.15 & 2.05 & 7.61 & 3345 \\
\hline \multirow[t]{4}{*}{$1998-2010$} & LIC & 0.10 & 0.05 & 0.76 & 0.00 & 0.13 & 1.86 & 7.10 & 517 \\
\hline & MIC & 0.10 & 0.06 & 0.88 & 0.00 & 0.14 & 2.06 & 8.02 & 1204 \\
\hline & $\mathrm{HIC}$ & 0.06 & 0.02 & 0.68 & 0.00 & 0.10 & 2.23 & 8.60 & 669 \\
\hline & All & 0.09 & 0.05 & 0.88 & 0.00 & 0.13 & 2.12 & 8.47 & 2390 \\
\hline \multirow[t]{4}{*}{ 1971-2002 } & LIC & 0.10 & 0.04 & 0.76 & 0.00 & 0.14 & 1.97 & 7.15 & 975 \\
\hline & MIC & 0.11 & 0.06 & 0.94 & 0.00 & 0.16 & 2.00 & 7.07 & 2057 \\
\hline & HIC & 0.10 & 0.06 & 0.77 & 0.00 & 0.12 & 1.98 & 8.09 & 1178 \\
\hline & All & 0.11 & 0.06 & 0.94 & 0.00 & 0.15 & 2.05 & 7.65 & 4210 \\
\hline \multirow[t]{4}{*}{ 2003-2010 } & LIC & 0.09 & 0.05 & 0.72 & 0.00 & 0.12 & 1.86 & 6.93 & 332 \\
\hline & MIC & 0.10 & 0.05 & 0.88 & 0.00 & 0.13 & 2.09 & 8.50 & 764 \\
\hline & HIC & 0.05 & 0.01 & 0.68 & 0.00 & 0.09 & 2.56 & 11.48 & 429 \\
\hline & All & 0.08 & 0.04 & 0.88 & 0.00 & 0.12 & 2.19 & 9.07 & 1525 \\
\hline
\end{tabular}


Table A2: Norm Values in the Last Decile by Income Group

\begin{tabular}{|c|c|c|c|c|}
\hline Year & Low Income & Middle Income & High Income & All \\
\hline$\overline{1971}$ & $9 / 26$ & $12 / 48$ & $9 / 29$ & $30 / 103$ \\
\hline 1972 & $3 / 27$ & $8 / 48$ & $3 / 29$ & 14104 \\
\hline 1973 & $8 / 28$ & $12 / 50$ & $13 / 30$ & $33 / 107$ \\
\hline 1974 & $4 / 27$ & $4 / 51$ & $3 / 31$ & $11 / 110$ \\
\hline 1975 & $2 / 27$ & $4 / 49$ & $5 / 31$ & $11 / 107$ \\
\hline 1976 & $4 / 26$ & $7 / 51$ & $4 / 31$ & $15 / 108$ \\
\hline 1977 & $1 / 26$ & $2 / 52$ & $6 / 34$ & $9 / 112$ \\
\hline 1978 & $4 / 26$ & $7 / 53$ & $4 / 36$ & $15 / 115$ \\
\hline 1979 & $1 / 26$ & $8 / 53$ & $4 / 36$ & $13 / 115$ \\
\hline 1980 & $1 / 27$ & $7 / 55$ & $2 / 36$ & $10 / 118$ \\
\hline 1981 & $1 / 27$ & $7 / 56$ & $1 / 36$ & $9 / 119$ \\
\hline 1982 & $3 / 30$ & $9 / 58$ & $1 / 37$ & $13 / 125$ \\
\hline 1983 & $3 / 31$ & $9 / 63$ & $3 / 37$ & $15 / 131$ \\
\hline 1984 & $3 / 31$ & $4 / 65$ & $2 / 37$ & $9 / 133$ \\
\hline 1985 & $1 / 33$ & $8 / 66$ & $1 / 37$ & $10 / 136$ \\
\hline 1986 & $4 / 33$ & $7 / 70$ & $3 / 37$ & $14 / 140$ \\
\hline 1987 & $1 / 33$ & $6 / 70$ & $0 / 39$ & $7 / 142$ \\
\hline 1988 & $1 / 33$ & $2 / 70$ & $2 / 39$ & $5 / 142$ \\
\hline 1989 & $3 / 35$ & $8 / 71$ & $1 / 39$ & $8 / 145$ \\
\hline 1990 & $2 / 35$ & $5 / 72$ & $1 / 39$ & $9 / 146$ \\
\hline 1991 & $2 / 34$ & $5 / 73$ & $2 / 39$ & $9 / 146$ \\
\hline 1992 & $2 / 34$ & $10 / 73$ & $1 / 39$ & $13 / 146$ \\
\hline 1993 & $1 / 34$ & $12 / 73$ & $5 / 40$ & $18 / 147$ \\
\hline 1994 & $5 / 34$ & $13 / 74$ & $3 / 40$ & $21 / 148$ \\
\hline 1995 & $6 / 33$ & $8 / 75$ & $0 / 40$ & $14 / 148$ \\
\hline 1996 & $6 / 34$ & $14 / 78$ & $2 / 40$ & $22 / 152$ \\
\hline 1997 & $4 / 35$ & $15 / 88$ & $4 / 48$ & $23 / 171$ \\
\hline 1998 & $2 / 37$ & $10 / 88$ & $6 / 48$ & $18 / 173$ \\
\hline 1999 & $3 / 38$ & $15 / 88$ & $4 / 48$ & $22 / 174$ \\
\hline 2000 & $8 / 38$ & $12 / 89$ & $0 / 48$ & $20 / 175$ \\
\hline 2001 & $3 / 37$ & $8 / 87$ & $5 / 48$ & $16 / 172$ \\
\hline 2002 & $4 / 37$ & $6 / 86$ & $1 / 48$ & $11 / 171$ \\
\hline 2003 & $4 / 38$ & $8 / 87$ & $2 / 48$ & $14 / 173$ \\
\hline 2004 & $2 / 38$ & $9 / 87$ & $2 / 48$ & $13 / 173$ \\
\hline 2005 & $5 / 37$ & $6 / 87$ & $1 / 47$ & $12 / 172$ \\
\hline 2006 & $1 / 37$ & $5 / 84$ & $3 / 47$ & $9 / 168$ \\
\hline 2007 & $4 / 36$ & $4 / 84$ & $2 / 48$ & $10 / 167$ \\
\hline 2008 & $1 / 36$ & $17 / 83$ & $3 / 48$ & $21 / 167$ \\
\hline 2009 & $6 / 37$ & $10 / 83$ & $1 / 48$ & $17 / 168$ \\
\hline 2010 & $5 / 36$ & $3 / 83$ & $1 / 47$ & $9 / 166$ \\
\hline Total & $131 / 1,307$ & $326 / 2,821$ & $116 / 1,607$ & $573 / 5,735$ \\
\hline (\%) & 10.0 & 11.5 & 7.2 & 10.0 \\
\hline
\end{tabular}

Note: Norm values over 0.2753 are in the last decile in the sample. Each numerator gives the number of such norms in the relevant portion of the sample, while the denominator gives the corresponding number of countries. Overall, the pattern of large policy changes follows the pattern of the means. The richest economies have the fewest large changes in their trilemma policies, while the middle-income group has the highest proportion of large changes. 
Table A3: Descriptive Statistics of Trilemma-Implied Norms by Country

\begin{tabular}{|c|c|c|c|c|c|c|c|}
\hline & Mean & Median & Max. & Min. & St. Dev. & Skew. & Kurt. \\
\hline Algeria & 0.09 & 0.08 & 0.24 & 0.01 & 0.06 & 0.71 & 3.21 \\
\hline Argentina & 0.18 & 0.11 & 0.68 & 0.00 & 0.21 & 1.53 & 3.96 \\
\hline Austria & 0.05 & 0.00 & 0.30 & 0.00 & 0.09 & 1.84 & 4.87 \\
\hline Bahamas, The & 0.01 & 0.00 & 0.24 & 0.00 & 0.05 & 4.80 & 24.04 \\
\hline Bangladesh & 0.17 & 0.19 & 0.42 & 0.00 & 0.14 & 0.23 & 1.92 \\
\hline Barbados & 0.02 & 0.00 & 0.24 & 0.00 & 0.07 & 3.18 & 11.08 \\
\hline Belgium & 0.07 & 0.02 & 0.54 & 0.00 & 0.13 & 2.44 & 8.24 \\
\hline Benin & 0.01 & 0.00 & 0.24 & 0.00 & 0.05 & 4.80 & 24.04 \\
\hline Bolivia & 0.14 & 0.06 & 0.67 & 0.00 & 0.16 & 1.80 & 5.95 \\
\hline Botswana & 0.15 & 0.16 & 0.32 & 0.01 & 0.09 & 0.12 & 1.85 \\
\hline Brazil & 0.12 & 0.08 & 0.55 & 0.00 & 0.12 & 2.08 & 7.58 \\
\hline Burundi & 0.10 & 0.08 & 0.34 & 0.01 & 0.08 & 1.50 & 4.78 \\
\hline Cameroon & 0.03 & 0.00 & 0.24 & 0.00 & 0.08 & 2.41 & 6.80 \\
\hline Canada & 0.06 & 0.06 & 0.15 & 0.01 & 0.04 & 0.65 & 2.85 \\
\hline Central African & 0.02 & 0.00 & 0.24 & 0.00 & 0.07 & 3.18 & 11.08 \\
\hline Chad & 0.02 & 0.00 & 0.24 & 0.00 & 0.07 & 3.18 & 11.08 \\
\hline Chile & 0.13 & 0.07 & 0.43 & 0.00 & 0.13 & 1.32 & 3.42 \\
\hline China & 0.12 & 0.01 & 0.66 & 0.00 & 0.19 & 1.73 & 5.06 \\
\hline Colombia & 0.12 & 0.10 & 0.55 & 0.02 & 0.11 & 2.24 & 9.22 \\
\hline Comoros & 0.00 & 0.00 & 0.06 & 0.00 & 0.01 & 4.80 & 24.04 \\
\hline Congo, Rep. & 0.02 & 0.00 & 0.24 & 0.00 & 0.07 & 3.18 & 11.08 \\
\hline Costa Rica & 0.12 & 0.09 & 0.32 & 0.00 & 0.09 & 0.63 & 2.26 \\
\hline Côte d'Ivoire & 0.03 & 0.00 & 0.24 & 0.00 & 0.08 & 2.41 & 6.80 \\
\hline Denmark & 0.11 & 0.07 & 0.31 & 0.00 & 0.12 & 0.57 & 1.74 \\
\hline Dominica & 0.06 & 0.00 & 0.29 & 0.00 & 0.11 & 1.31 & 2.76 \\
\hline Dominican Republic & 0.21 & 0.17 & 0.69 & 0.02 & 0.18 & 1.68 & 4.95 \\
\hline Egypt, Arab Rep. & 0.25 & 0.13 & 0.88 & 0.00 & 0.28 & 0.73 & 2.26 \\
\hline El Salvador & 0.11 & 0.00 & 0.64 & 0.00 & 0.18 & 1.73 & 4.77 \\
\hline Equatorial Guinea & 0.02 & 0.00 & 0.24 & 0.00 & 0.07 & 3.18 & 11.08 \\
\hline
\end{tabular}


Table A3 - continued from previous page

Mean Median Max. Min. St. Dev. Skew. Kurt.

\begin{tabular}{|c|c|c|c|c|c|c|c|}
\hline Fiji & 0.09 & 0.07 & 0.24 & 0.01 & 0.07 & 0.77 & 2.32 \\
\hline Finland & 0.07 & 0.01 & 0.38 & 0.00 & 0.10 & 1.78 & 5.83 \\
\hline France & 0.07 & 0.02 & 0.30 & 0.00 & 0.09 & 0.98 & 2.87 \\
\hline Gabon & 0.01 & 0.00 & 0.24 & 0.00 & 0.05 & 4.80 & 24.04 \\
\hline Gambia, The & 0.10 & 0.07 & 0.68 & 0.00 & 0.14 & 3.11 & 13.19 \\
\hline Germany & 0.07 & 0.04 & 0.23 & 0.00 & 0.06 & 1.61 & 4.63 \\
\hline Greece & 0.09 & 0.05 & 0.36 & 0.00 & 0.11 & 1.22 & 3.34 \\
\hline Grenada & 0.04 & 0.00 & 0.41 & 0.00 & 0.11 & 2.23 & 6.66 \\
\hline Guatemala & 0.13 & 0.11 & 0.65 & 0.00 & 0.14 & 2.20 & 9.05 \\
\hline Guyana & 0.21 & 0.16 & 0.71 & 0.00 & 0.22 & 0.91 & 2.80 \\
\hline Honduras & 0.15 & 0.07 & 0.69 & 0.00 & 0.21 & 1.64 & 4.58 \\
\hline Iceland & 0.11 & 0.09 & 0.39 & 0.00 & 0.09 & 1.47 & 5.08 \\
\hline India & 0.10 & 0.06 & 0.61 & 0.00 & 0.15 & 2.35 & 7.97 \\
\hline Indonesia & 0.14 & 0.06 & 0.64 & 0.01 & 0.19 & 1.99 & 5.50 \\
\hline Ireland & 0.08 & 0.03 & 0.47 & 0.00 & 0.12 & 1.89 & 5.82 \\
\hline Israel & 0.11 & 0.09 & 0.40 & 0.00 & 0.09 & 1.57 & 5.83 \\
\hline Italy & 0.10 & 0.07 & 0.44 & 0.00 & 0.13 & 1.02 & 3.11 \\
\hline Jamaica & 0.18 & 0.17 & 0.43 & 0.00 & 0.12 & 0.30 & 2.12 \\
\hline Japan & 0.06 & 0.05 & 0.17 & 0.00 & 0.05 & 0.70 & 2.37 \\
\hline Jordan & 0.07 & 0.04 & 0.40 & 0.00 & 0.10 & 1.77 & 5.49 \\
\hline Kenya & 0.10 & 0.05 & 0.50 & 0.00 & 0.12 & 2.00 & 6.98 \\
\hline Korea, Rep. & 0.08 & 0.05 & 0.30 & 0.00 & 0.08 & 1.10 & 3.34 \\
\hline Madagascar & 0.10 & 0.07 & 0.26 & 0.00 & 0.08 & 0.61 & 2.11 \\
\hline Malaysia & 0.14 & 0.08 & 0.72 & 0.00 & 0.16 & 1.97 & 7.17 \\
\hline Maldives & 0.11 & 0.06 & 0.47 & 0.00 & 0.12 & 1.36 & 4.26 \\
\hline Mali & 0.01 & 0.00 & 0.24 & 0.00 & 0.05 & 4.80 & 24.04 \\
\hline Mauritania & 0.12 & 0.12 & 0.39 & 0.00 & 0.09 & 0.80 & 3.84 \\
\hline Mauritius & 0.11 & 0.08 & 0.28 & 0.00 & 0.08 & 0.76 & 2.41 \\
\hline Mexico & 0.18 & 0.15 & 0.58 & 0.00 & 0.14 & 1.12 & 3.91 \\
\hline
\end{tabular}


Table A3 - continued from previous page

Mean Median Max. Min. St. Dev. Skew. Kurt.

\begin{tabular}{|c|c|c|c|c|c|c|c|}
\hline Morocco & 0.07 & 0.05 & 0.21 & 0.00 & 0.07 & 0.82 & 2.24 \\
\hline Netherlands & 0.09 & 0.00 & 0.50 & 0.00 & 0.14 & 1.66 & 4.93 \\
\hline Nicaragua & 0.15 & 0.00 & 0.70 & 0.00 & 0.24 & 1.51 & 3.59 \\
\hline Niger & 0.01 & 0.00 & 0.24 & 0.00 & 0.05 & 4.07 & 19.04 \\
\hline Nigeria & 0.15 & 0.11 & 0.72 & 0.00 & 0.17 & 2.18 & 7.48 \\
\hline Norway & 0.09 & 0.09 & 0.29 & 0.00 & 0.07 & 0.99 & 3.86 \\
\hline Pakistan & 0.15 & 0.15 & 0.38 & 0.00 & 0.12 & 0.34 & 2.06 \\
\hline Panama & 0.00 & 0.00 & 0.00 & 0.00 & 0.00 & . & \\
\hline Papua New Guinea & 0.11 & 0.09 & 0.30 & 0.00 & 0.09 & 0.77 & 2.53 \\
\hline Paraguay & 0.16 & 0.11 & 0.68 & 0.00 & 0.17 & 2.22 & 7.27 \\
\hline Peru & 0.17 & 0.14 & 0.54 & 0.00 & 0.14 & 1.09 & 3.54 \\
\hline Philippines & 0.16 & 0.14 & 0.58 & 0.00 & 0.15 & 1.14 & 3.89 \\
\hline Portugal & 0.08 & 0.02 & 0.50 & 0.00 & 0.13 & 1.71 & 5.26 \\
\hline Rwanda & 0.10 & 0.06 & 0.31 & 0.00 & 0.09 & 0.97 & 2.98 \\
\hline Samoa & 0.08 & 0.07 & 0.29 & 0.01 & 0.07 & 1.27 & 4.88 \\
\hline Saudi Arabia & 0.02 & 0.00 & 0.31 & 0.00 & 0.06 & 3.74 & 17.26 \\
\hline Senegal & 0.01 & 0.00 & 0.24 & 0.00 & 0.05 & 4.80 & 24.04 \\
\hline Seychelles & 0.13 & 0.08 & 0.61 & 0.00 & 0.17 & 1.74 & 5.21 \\
\hline Sierra Leone & 0.14 & 0.10 & 0.69 & 0.02 & 0.15 & 2.19 & 7.99 \\
\hline Singapore & 0.11 & 0.07 & 0.54 & 0.00 & 0.13 & 1.91 & 6.49 \\
\hline Solomon Islands & 0.14 & 0.08 & 0.65 & 0.00 & 0.17 & 1.50 & 4.64 \\
\hline South Africa & 0.08 & 0.08 & 0.26 & 0.00 & 0.06 & 0.82 & 3.42 \\
\hline Spain & 0.08 & 0.02 & 0.40 & 0.00 & 0.11 & 1.33 & 3.95 \\
\hline Sri Lanka & 0.16 & 0.10 & 0.45 & 0.01 & 0.14 & 0.72 & 2.19 \\
\hline St. Lucia & 0.05 & 0.00 & 0.29 & 0.00 & 0.11 & 1.59 & 3.57 \\
\hline St. Vincent and & 0.02 & 0.00 & 0.24 & 0.00 & 0.07 & 3.18 & 11.08 \\
\hline Swaziland & 0.01 & 0.00 & 0.24 & 0.00 & 0.05 & 4.80 & 24.04 \\
\hline Sweden & 0.08 & 0.08 & 0.18 & 0.01 & 0.04 & 0.30 & 2.85 \\
\hline Thailand & 0.10 & 0.05 & 0.52 & 0.00 & 0.13 & 2.08 & 6.69 \\
\hline
\end{tabular}


Table A3 - continued from previous page

Mean Median Max. Min. St. Dev. Skew. Kurt.

\begin{tabular}{llllllll}
\hline Togo & 0.00 & 0.00 & 0.00 & 0.00 & 0.00 &. &. \\
Trinidad and Tobago & 0.13 & 0.01 & 0.73 & 0.00 & 0.19 & 1.49 & 4.81 \\
Tunisia & 0.10 & 0.09 & 0.24 & 0.01 & 0.06 & 0.87 & 2.65 \\
Turkey & 0.09 & 0.07 & 0.25 & 0.01 & 0.07 & 0.68 & 2.18 \\
Uganda & 0.15 & 0.07 & 0.69 & 0.00 & 0.18 & 1.83 & 5.89 \\
United Kingdom & 0.09 & 0.05 & 0.27 & 0.00 & 0.08 & 1.01 & 2.85 \\
Uruguay & 0.16 & 0.16 & 0.45 & 0.01 & 0.11 & 0.77 & 3.18 \\
Venezuela, RB & 0.18 & 0.07 & 0.72 & 0.00 & 0.23 & 1.54 & 4.04 \\
Zambia & 0.13 & 0.11 & 0.53 & 0.01 & 0.11 & 2.05 & 8.27 \\
\hline Total & 0.10 & 0.05 & 0.88 & 0.00 & 0.13 & 2.20 & 8.83 \\
\hline
\end{tabular}

Note: The table reports descriptive statistics of the trilemma implied norm for each country in the dataset. 


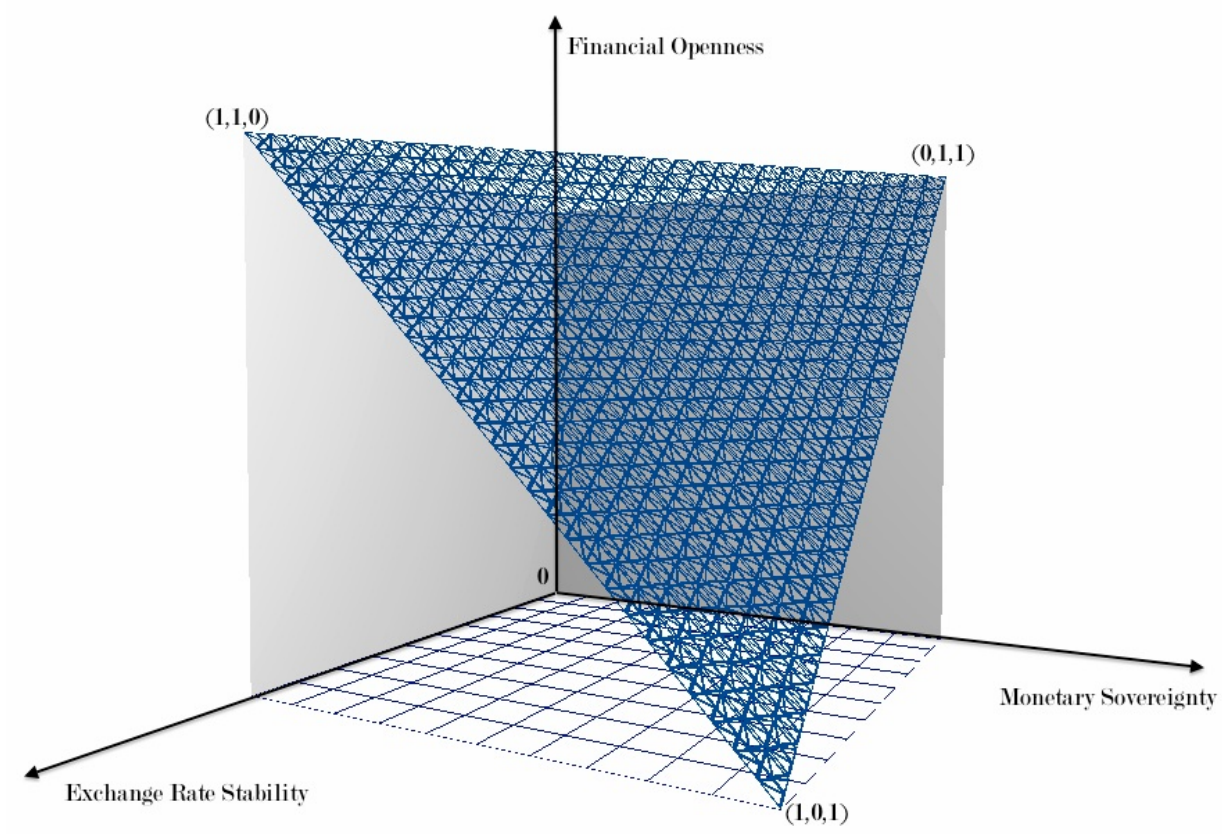

Figure A1: The Trilemma Constraint. This figure depicts a particular, linear form of the trilemma constraint; namely, with the indicators of exchange rate stability, financial openness, and monetary sovereignty each normalized between zero and one, they sum to two. 


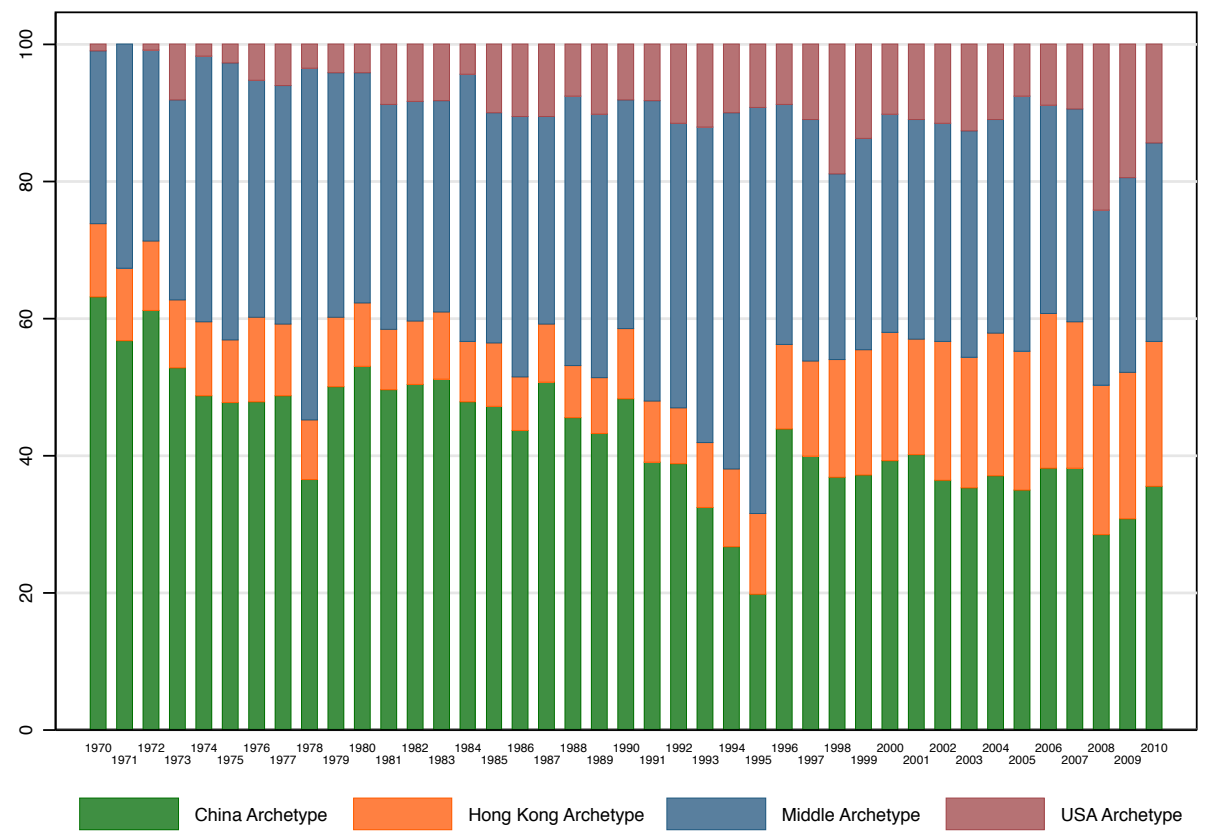

Figure A2: Countries per Archetype (percent). The figure shows the number of economies in each year of each type. Throughout much of the modern period, the most common arrangement in this taxonomy is the 'China' type, with its relatively stable exchange rates and a relatively high degree of monetary sovereignty. The second most common arrangement type is the 'Middle.' The number of 'Middle' observations rose through the early nineties as many 'China' type economies began to relax some of their capital controls. The number of economies of the 'Hong Kong' type has been rising fairly steadily since the nineties. The number of economies of the ' $U . S$.' type has risen throughout the period, though less steadily. 